\title{
Tierra, trabajo y reforma agraria en la Segunda República española (1931-1936): algunas consideraciones críticas
}

\author{
RicARdo Robledo y ÁNGEl Luis GonZÁLEZ EsTEBAN
}

\begin{abstract}
PALABRAS CLAVE: reforma agraria, latifundismo, mercado laboral, desigualdad.
\end{abstract}

CÓDIGOS JEL: Q15, Q18, J43, N54.

lenfoque habitual de la reforma agraria tiende a ser negativo, algo que la
misma brevedad del régimen republicano y su violenta interrupción tienden
a favorecer. En este texto se analiza primero la tesis del desarrollo de un mer-
cado activo y muy eficiente de las reformas liberales decimonónicas frente a la ineficiencia
y contradicciones de la reforma agraria del siglo Xx. En la segunda parte, la crítica his-
toriográfica se centra en las recientes investigaciones que atribuyen a la política labo-
ral, inaugurada por los socialistas en 1931, la principal causa de la conflictividad so-
cial e, incluso, la responsabilidad en la derechización del pequeño y mediano campesino.

Nuestro propósito es defender la viabilidad de la reforma agraria y hacer comprensible que el desarrollo de una reforma laboral favorable a los trabajadores del campo tuviera diversos costes de adaptación al principio. Entre ellos no fue despreciable la hostilidad de los grandes labradores a planteamientos de negociación colectiva que sintonizaban con la institucionalización de las políticas sociales de otros países. 


\section{Land, labour and agrarian reform in the Spanish Second Republic (1931-36): a critique and some considerations}

\section{KEYWORDS: land reform, latifundia, labour market, inequality.}

\section{JEL CODES: Q15, Q18, J43, N54.}

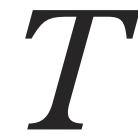

The brief existence of the Second Republic and its violent end tend to favor the usual negative view of land reform. This article analyzes the perceptions of inefficiency and contradictory effects of the twentieth-century agricultural reform, in contrast with the thesis of an active and extremely efficient market following the liberal reforms of the nineteenth century. The second part of the paper focuses on recent historiographical research that considers the main cause of pre-Civil War social unrest to have been the labor policy launched by the Socialists in 1931, which was also seen as a decisive factor in the swing towards the right of mid-and small-scale farmers. This article defends the viability of an agricultural reform that proved beneficial for the average farm worker. The initial costs of adaptation to the reform are explained, along with the hostility of Spain's large-scale farmers to collective bargaining, an approach which had been institutionalized elsewhere through social policies.

Recepción: 2016-01-30 - Revisión: 2016-08-15 - Aceptación: 2016-08-17

Ricardo Robledo es catedrático jubilado de Historia Económica de la Universidad de Salamanca. Investigador visitante de la Universitat Pompeu Fabra. Dirección para correspondencia: Departamento de Humanidades, Universitat Pompeu Fabra, cl Ramon Trías Fargas, 25-27, 08005 Barcelona (España). C.e.: rrobledo@usal.es

Ángel Luis González Esteban es doctorando en Historia Económica en la Universidad de Barcelona. Dirección para correspondencia: Departamento de Economía e Historia Económica, Facultad de Economía y Empresa, Universidad de Salamanca, Campus Miguel de Unamuno, 37007 Salamanca (España). C.e.: algonzal@usal.es 
"Antes me cortaría una mano que consentir que trabajasen mi casa asociados de la Casa del Pueblo.» ${ }^{1}$

"Que siga la reforma social, limitemos la propiedad; más no abandonemos a la Guardia civil y armémonos hasta los dientes.»²

\section{INTRODUCCIÓN ${ }^{3}$}

Los estudiosos de las reformas agrarias han ido enriqueciendo su tratamiento integrándolas en una amplia estrategia de desarrollo rural, mucho más necesaria en un mundo globalizado que en el período de desarrollo introvertido de entreguerras, cuando el acceso a la tierra tenía un protagonismo ineludible ${ }^{4}$. Este protagonismo se acentuó en España, un país con débil pulso industrial y de una gran desigualdad en la propiedad de la tierra, con motivo de la crisis económica, pero también de las oportunidades que abrió la nueva coyuntura política. Economistas, juristas, filósofos, literatos, notarios y políticos de todas las tendencias elucubraron con mayor o menor acierto sobre el problema social agrario (Robledo, 2008). El tema de la reforma agraria republicana fue también uno de los más influyentes entre los historiadores de las décadas de 1970-1980. La obra de Malefakis (1971) colaboró a ello. Posteriormente perdió cierta capacidad de atracción, aunque no han dejado de publicarse monografías, más de un centenar entre 1996-2016 (Robledo, 2017). En términos económicos el conjunto de medidas de la política agraria republicana afectó plenamente tanto a la tierra como al trabajo. Eso quiere decir que el proceso reformista repercutió plenamente en unas economías agrarias poco capitalizadas. Sin duda el mercado de la tierra de las regiones latifundistas resultó afectado por la Ley de Bases de la Reforma Agraria, sin olvidar que el Inventario de Fincas Expropiables incluyó a todas las provincias españolas.Y en todas también trascendieron los cambios en el uso de la tierra (legislación sobre arrendamientos o rabassa). Por último, ninguna población se libró, en teoría, de la regulación del mercado de trabajo que por primera vez concedió determinados derechos a los trabajadores del campo.

1. La Opinión, 3 de octubre de 1931, citado en NAVARRo (2000: 95).

2. Royo, Diario de Sesiones de las Cortes (DSSC), 21 de noviembre de 1934, p. 4.918.

3. El apartado 1 coincide básicamente con lo expuesto en Robledo y GoNZÁLEZ EsTEBAN (2016: 11-22).

4. Un ejemplo significativo de la nueva perspectiva integradora en el tratamiento de la reforma agraria puede encontrarse en BANCO MUNDIAL (2008). Algunos aspectos de este nuevo campo de discusión, enfocados desde la óptica de las nuevas organizaciones internacionales campesinas, han sido resumidos en GoNZÁLEZ EsTEBAN (2014). 
Está claro que la modificación de los derechos de la tierra y del trabajo, sobre los que se centra este trabajo, es algo más que la alteración de los factores de producción, pues cambian a la vez las relaciones sociales o los intereses políticos. Esto hace complicado abordar el estudio de la reforma agraria republicana con herramientas solamente económicas en un momento en que surgieron expectativas, formas de organización social y de conflictividad que resultaron novedosas en la sociedad rural.

El enfoque habitual de la reforma agraria tiende a ser negativo, algo que la misma brevedad del régimen republicano y su violenta interrupción tienden a favorecer. La obra de Malefakis, con varios capítulos que soportan bien el paso del tiempo, concluye con un epílogo discutible en el que sorprenden afirmaciones como que la naturaleza democrática del régimen republicano contribuyó al fracaso de la reforma agraria (1971: 448). Parece una paradoja, pues precisamente la reforma se planteó para conseguir la definitiva consolidación en España de una República democrática, según expuso el ministro de Agricultura Ruiz-Funes cuando daba el máximo impulso a la reforma en junio de 1936 (RuizFunes, 1936: 714). Buena parte de la literatura económica que está surgiendo en torno al crecimiento actual de la desigualdad ayuda a interpretar la necesidad de la reforma agraria en esa clave de fortalecimiento de la democracia ${ }^{5}$.

Nuestro planteamiento no pierde de vista esa apreciación. Por eso, el objetivo de este artículo es analizar la solidez de las investigaciones que han cuestionado recientemente la necesidad y oportunidad de la reforma agraria, tesis que se analiza en el primer apartado, mientras que en el segundo nos referimos a la política laboral. Aunque parezca obvio, queremos manifestar que el tono crítico adoptado no supone despreciar el punto de vista comentado o el esfuerzo en la elaboración de los datos. Es un ejercicio de crítica historiográfica que puede ayudar al debate sobre la conveniencia o no de las reformas distributivas.

\section{LAS FUERZAS DEL MERCADO FRENTE A LAS DE LA REFORMA AGRARIA}

No es muy entusiasta el tratamiento de la reforma agraria en los manuales de historia económica (Riesco, 2016). La orientación viene de lejos. La idea de una reforma agraria ineficiente a medio-largo plazo fue expuesta por Simpson (1997: 295-296, 315) hace veinte años fijándose en los problemas de la sobreproducción de trigo, de la parcelación inade-

5. La igualdad política que requiere la democracia siempre está bajo la amenaza de la desigualdad económica y, cuanto más extrema es la desigualdad económica, mayor es a la amenaza a la democracia (Gilens, 2012, citado por DeATon, 2015: 243). 
cuada para incrementar el bienestar, de la escasa preparación técnica de los asentados y de la reducción de la renta que traería la baja productividad del trabajo, temas todos que se han vuelto a abordar quince o veinte años después (Robledo \& González Esteban, 2016: 11-13). Aquí nos centraremos principalmente en el estudio de Carmona y Rosés (2011) y Carmona, Rosés y Simpson (2015), por la ruptura que significa con un discurso muy influyente en la historia social y económica española. En sus diferentes versiones se valora positivamente el cambio institucional adscrito a las reformas agrarias liberales como buen ejemplo de prototypical market-oriented reform, opinión que no evita cierto reduccionismo al no tener en cuenta las variables fiscales y políticas que condicionaron las desamortizaciones de Mendizábal y Madoz. En cambio se cuestionan las intervenciones de carácter redistributivo, como las de la reforma agraria republicana ${ }^{6}$. Para ello, se analizan los cambios en la estructura social del agro español, el descenso en el número de jornaleros, y la evolución del precio de la tierra comparado con los salarios. Si en el censo de 1860 España tenía 1,6 millones de jornaleros y setenta años después se había pasado a menos del millón $(0,950)$, ¿para qué era preciso una reforma adicional? vienen a decir los autores, que hacen otros laboriosos cálculos para estimar el número de propietarios o jornaleros en los años 1890 y 1910.

Ahora bien, una cosa es que hubiera mejoras sociales en el período 1860-1930, y otra muy diferente que la situación en los años treinta fuera, si no óptima, razonablemente buena. Si los autores no entran a valorar las posibilidades de una government initiated land distribution (Carmona \& Rosés, 2011), ¿por qué negar a priori la posibilidad de acelerar un proceso de acceso a la tierra más rápido y efectivo que el que "el mercado» estaba generando? Sobre todo si se tiene presente la gravedad de las circunstancias socioeconómicas al inicio de la década de 1930. ¿Qué le importaba al agricultor sin tierra que el número de días de trabajo necesarios para comprar una parcela bajase de 1200 días a «sólo» 800 días entre 1910 y 1930 si, en la práctica, él nunca iba a poder reunir tal cantidad de dinero? Parece como si se quisieran utilizar las tendencias 1860-1930 para negar la existencia de un problema en los años treinta o su escasa influencia. Si volvemos a los cambios agrarios, puede ocurrir que la mejora de una variable como la del descenso del número de jornaleros no tenga por qué suponer necesariamente mejoras en la distribución de la renta. Después de la parcelación y el declive del latifundismo en Aguilar de la Frontera, la especialización y la intensificación de cultivos acrecentaron la desigualdad en la distribución del ingreso de modo que el $5 \%$ de las familias acumulaba cerca del $75 \%$ del excedente agrario (López Estudillo, 2011).Y en tierras de regadío de Orihuela el índice de concentración de Gini se había incrementado del 0,787 en 1830 al 0,866 de medio siglo después (Millán, 1999: 103).

6. Para este diferente juicio entre unas y otras reformas, RobLEDo y LóPEZ (2007: 10-17). 
Las limitaciones de espacio nos impiden comentar diversos supuestos asumidos en los trabajos de Carmona y Rosés (2011) y Carmona, Rosés y Simpson (2015). No obstante, nos parece importante señalar que el supuesto de competencia perfecta en el mercado de trabajo y en el de la tierra resulta algo arriesgado. No parece que tal como funcionaba el mercado rural español, sobre todo en el sur, pueda aplicársele la condición de competencia perfecta. Competencia la había, y mucha, en el lado de la oferta con un elevado número de trabajadores, españoles y portugueses, disputándose el empleo unos pocos meses al año. Pero desde la demanda la situación era más bien de monopsonio cuando el manijero seleccionaba en la plaza la mano de obra que interesaba para el cortijo. La información, que favorece al empleador, pues solamente él controla la corriente de ingresos para pagar salarios, beneficios o renta, se hacía más asimétrica por la concentración de la propiedad y los ligámenes familiares de los dueños. Por último, el poder para controlar el salario tendía a favorecer a los propietarios hasta que en 1931 se ensayó la negociación colectiva, algo que se interpretó como el fin de la libertad de trabajo, sostenida hasta entonces con el recurso de la Guardia Civil, como veremos en el siguiente epígrafe (Rothschild, 1957: 144-147)

Respecto del mercado de la tierra, Carmona y Rosés (2011) afirman que la mejora en el acceso a la propiedad de la tierra (medida a través del descenso en los precios relativos de la tierra respecto de los salarios) no se habría dado sin un mercado de la tierra activo y eficiente: it should be emphasized that, without an efficient and active landmarket, it is likely that the concentration of land ownership increased as a consequence of countryside migrations and the subsequent decrease in the agrarian workforce (Carmona \& Roses, 2011: 3). Por tanto, presuponen que el descenso de la población agraria derivado de la emigración a las ciudades llevaría, ceteris paribus, a una mayor concentración de la tierra y que, si no lo hizo, fue gracias a las reformas liberales que hicieron eficiente el mercado de la tierra. De acuerdo con este razonamiento, el cambio estructural conduciría por sí solo a un incremento en el precio relativo de la tierra respecto de los salarios rurales, y esto es algo bastante discutible. En primer lugar, porque, como los mismos autores reconocen, las nuevas oportunidades en las ciudades condujeron a una disminución de la oferta de trabajo en el campo, lo que debería impulsar un alza en los salarios rurales. Es lo que percibieron los contemporáneos cuando se produjo la fuerte emigración castellana a América en los primeros decenios del siglo xx, tal como documentó Unamuno (Robledo, 1988).Y en segundo lugar, porque no consideramos descabellado que el abaratamiento del precio de la tierra -en caso de que se diera- fuera en parte debido a su menor demanda, como consecuencia del desplazamiento hacia nuevas oportunidades de inversión en la industria y los servicios. En otras palabras, es posible que el proceso de mejora en la ratio salarios rurales/precio de la tierra estuviera en realidad parcialmente motivado por el cambio estructural. En este sentido, aun asumiendo la validez de los datos 
manejados con relación a salarios rurales y precios de la tierra, resulta controvertido atribuir el posible «éxito» en términos de redistribución de la tierra exclusivamente a las reformas agrarias liberales.

El texto de Carmona, Rosés y Simpson (2015) se basa, por otra parte, en datos que pueden tener cierta debilidad. No profundizaremos en los precios de la tierra, cuestión clave sin duda, que proceden de las informaciones registrales. Es una fuente que no dio cuenta de innumerables transacciones y que ocultó por sistema el precio real del bien igual que siguen haciendo hoy los notarios-, de ahí que deba utilizarse con bastante prudencia ${ }^{7}$. El otro dato es el del número de jornaleros en la Segunda República, cuya calidad de información y grado de representación algunos profesores de la Universidad de Salamanca hemos empleado bastante tiempo en calibrar, lo que ha exigido pacientes cálculos. Como hemos afirmado, el Censo de Campesinos fue revisado por las Juntas de Reforma Agraria, aunque no se pudo evitar el absentismo electoral, lo que nos obligó a publicar información de tan sólo 28 provincias, aunque la tengamos de bastantes más.Y de esas 28 provincias faltan partidos judiciales. Esto nos forzó a la modestia -quizá excesiva-, si bien nuestros datos han respaldado diversas monografias de historia social y pueden ayudar con cautela a interpretar los cambios en la estructura social. Habrá que ver si los datos que publicamos en 2007 (Espinoza et al., 2007), y que utilizan los autores, son muestra consistente para deducir a partir de ahí el número de jornaleros para casi toda España, como han expuesto Carmona, Rosés y Simpson (2015). Hoy creemos que, en los pueblos que enviaron datos, hubo mayor subregistro del que pensábamos ${ }^{8}$.

La comparación de censos demográficos con los censos "políticos» tiene sus riesgos, pues los objetivos y los medios de unos y otros son distintos. En 1930 únicamente se están teniendo en cuenta los jornaleros, propietarios y arrendatarios registrados en el Censo de Campesinos de la Segunda República, es decir, aquellos que reunían los requisitos para inscribirse. Aun así creemos que el historiador debe saber aprovechar la información disponible igual que debemos alabar el esfuerzo de los autores que criticamos por llegar a una interpretación generalista. Es esa intención la que nos mueve a presentar la comparación $1860-1930^{\circ}$. Nos basamos en una amplia muestra de 258 partidos judiciales que representan la casi totalidad de las provincias latifundistas. La escala de partido judicial nos parece que ofrece el nivel de agregación suficiente para efectuar comparaciones y evitar errores de atribución, pues hay varias provincias que no tienen in-

7. Congost y García Orallo (2015: 12) llaman también la atención sobre las peculiaridades de la fuente.

8. Diversos datos que avalan esta sospecha se exponen en Robledo y GonZÁLEZ EsTEBAN (2016).

9. Hemos redondeado, pues la fecha del Censo de Campesinos es probablemente de 1934-1936. 
formación para todos los partidos. Estos 258 partidos judiciales ${ }^{10}$ representan aproximadamente el $44 \%$ de la población total española en 1930, advirtiendo que se ha descontado la población de nueve capitales de provincia (por considerarse que dichas capitales no pertenecen al ámbito rural que se quiere estudiar).

Nuestro punto de atención para la comparación se va a centrar en medir el peso de los jornaleros en el conjunto del campesinado aspirante a la reforma. Aunque el pequeño propietario/arrendatario puede convertirse en jornalero a tiempo parcial ${ }^{11}$, como ocurre hoy en la agricultura española, nos parece relevante evaluar específicamente la importancia de la salarización. Las fronteras entre esas categorías pueden ser algo difusas, pero creemos que hay una diferencia significativa entre el jornalero, el considerado tradicionalmente un proletario, y el pequeño campesino que pagaba una contribución de hasta 50 pesetas anuales. La hipótesis de la que partimos es que en 1930 hubo un subregistro que no afectó a la estructura relativa de los datos. Es decir, por poner un ejemplo, la influencia del anarquismo, enemigo de las «reformas burguesas», hace poco representativas las cifras provinciales de Cádiz, pero en los pueblos censados no se apuntaron más jornaleros o menos pequeños propietarios. En consecuencia las cifras absolutas de jornaleros pueden ser discutibles, pero no tanto las relativas.

Con estos supuestos y los ajustes necesarios ${ }^{12}$, podemos acercarnos a los cambios entre el censo de 1860 y el de campesinos de 1930. Llamamos tasa de salarización ${ }^{13}$ al porcentaje de jornaleros en el conjunto formado por jornaleros, pequeños arrendatarios y propietarios, y coeficiente de salarización al que mide la relación de los jornaleros respecto de los pequeños arrendatarios y propietarios.

10. Es importante tener en cuenta que, a lo largo del período estudiado, hubo varios cambios en la composición de determinados partidos judiciales: algunos desaparecieron o vieron modificada su definición territorial y también se crearon partidos nuevos. Sin embargo, en este artículo se ha trabajado con una muestra de partidos judiciales existentes tanto en 1860 como en 1930, período en que los cambios en términos de adscripción de municipios fueron poco importantes.

11. Como la parcela de tierra no les produce lo suficiente para mantenerse [...], de los 215 que figuran como propietarios, 150 trabajan a jornal. Información sobre Monroy, El Socialista, 10 de abril de 1925, p. 3.

12. Las cifras de jornaleros, propietarios y arrendatarios del Censo de Campesinos, disponibles a nivel municipal, se han extrapolado al nivel de partidos judiciales teniendo en cuenta el tanto por ciento de población que cubre la muestra (a través de una regla de tres).

13. Es distinta de la convencional tasa de asalarización, que mide la proporción de asalariados en el empleo total. 
TABLA 1

Variaciones experimentadas en el nivel de salarización en España en 1860 y 1930

\begin{tabular}{lrrc}
\hline & $\mathbf{1 8 6 0}$ & $\mathbf{1 9 3 0}$ & Crecimiento (\%) \\
\hline Tasa de salarización (J/JAP) & 56,42 & 49,16 & -13 \\
Coeficiente de salarización (J/A+P) & 1,29 & 0,97 & -25 \\
\hline
\end{tabular}

Fuente: elaboración propia a partir de los datos del Censo de Campesinos de la Segunda República (Espinoza et al., 2007) y Censo de Población de 1860.

\section{GRÁFICO 1}

Coeficientes de salarización en 1860 y en 1930 (por partidos judiciales) ${ }^{14}$

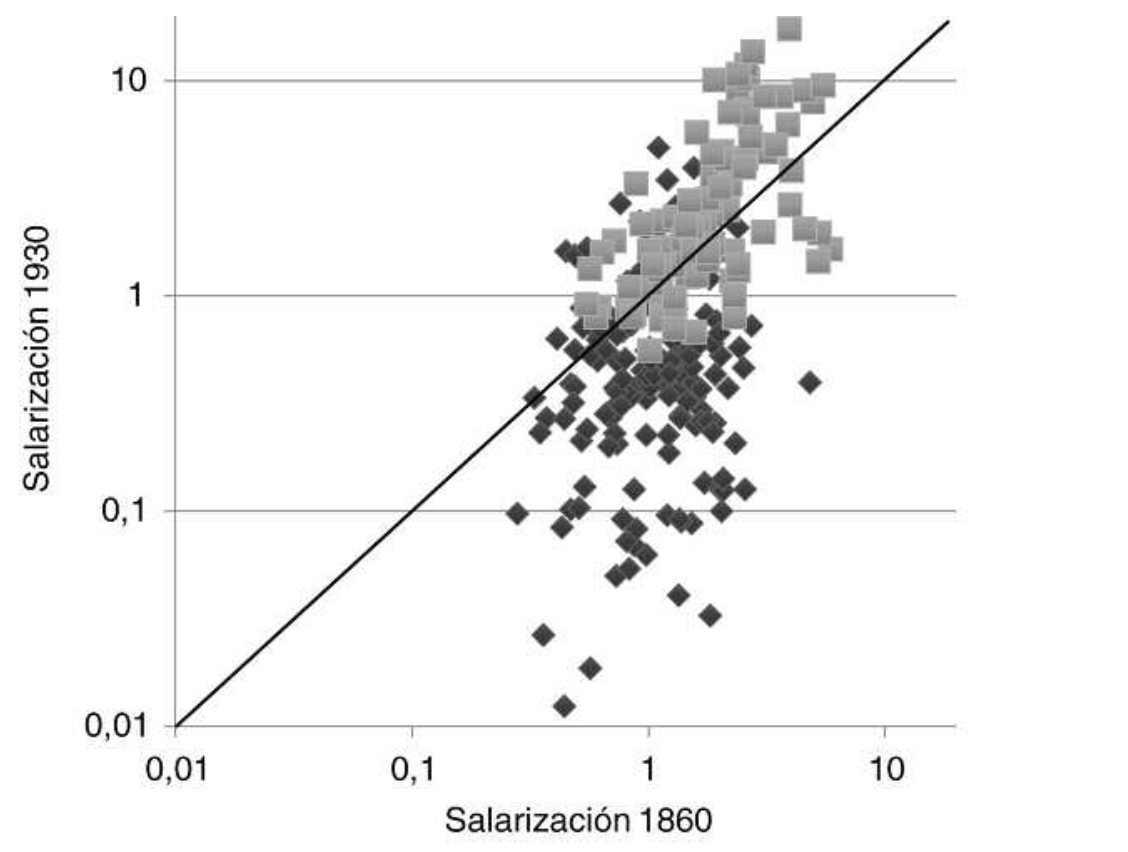

- Partidos resto de España $\quad$ Partidos Andalucía y Extremadura

Fuente: elaboración propia según Censo de Población de 1860 y Espinoza et al. (2007).

14. Ambos ejes han sido representados en escala logarítmica. Existen limitaciones en la comparabilidad de los datos, pues el Censo de Campesinos presenta un claro sesgo: los grandes propietarios y arrendatarios, que sí se contabilizaron en el Censo de 1860 (de cuantía escasa, por otra parte), no se inscribieron en 1930, mientras que sí tenderían a hacerlo todos los jornaleros sin tierra. Si se asume esta limitación, los puntos situados en la bisectriz se corresponderían con partidos judiciales en los que el coeficiente de salarización permanece inmutable entre 1860 y 1930 . Los puntos situados por encima de la bisectriz serían partidos en los que el coeficiente aumenta entre 1860 y 1930, mientras que los puntos situados por debajo representarían partidos en los que el coeficiente descendería en el período señalado. 
El número absoluto de jornaleros sin tierra descendió en un contexto de pérdida de población activa agraria (sobre todo a partir de 1910). Ésta es la tendencia general. Sin embargo, el análisis por partidos judiciales permite observar que dicha tendencia no fue compartida en todas las zonas. Avanzar hacia un nivel más desagregado nos ayuda a identificar partidos en los que el coeficiente de salarización no sólo no descendió, sino que aumentó considerablemente, alcanzando niveles ciertamente dramáticos, por ejemplo, en varios partidos de Andalucía occidental.

En el Gráfico 1 se han representado, en el eje x, los coeficientes de salarización en 1860, y en el eje y, los de 1930. Cada observación (cada punto en el gráfico) se corresponde con un partido judicial.

Como puede observarse, el coeficiente de salarización en 1860 tiene una alta capacidad explicativa del mismo coeficiente en 1930. La alta correlación observada podría estar relacionada con una cierta permanencia en el tiempo de una determinada distribución geográfica -a nivel nacional- en el tipo de cultivo y en la forma de explotación. Sin embargo, los datos revelan precisamente la incapacidad de las reformas agrarias liberales para corregir las notables diferencias regionales en el grado de acceso a la tierra. No solamente no existió un proceso de convergencia regional en el grado de acceso, sino que las diferencias entre regiones se acrecentaron considerablemente durante el período estudiado (nótese la diferencia en el grado de dispersión de los puntos a lo largo de ambos ejes).

El gráfico permite observar varias cuestiones adicionales. En primer lugar $-\mathrm{y}$ de nuevo asumiendo las limitaciones de comparabilidad en los datos-, existe un importante número de partidos en los que el coeficiente de salarización aumentó durante el período señalado. En segundo lugar, los partidos pertenecientes al suroeste peninsular ya eran los más afectados por el problema de acceso a la tierra en 1860. Finalmente, fue precisamente en estos partidos en los que, en promedio, más se agravó el problema durante los siguientes setenta años.

Si excluimos del análisis Andalucía y Extremadura, los datos manejados son consistentes con la hipótesis de una mejora significativa en el acceso a la tierra. Además, tal y como aseguran Robledo y González Esteban (2016), el nivel de salarización disminuyó más -en términos absolutos- en aquellos partidos que partían de niveles de salarización más altos. Éste sería, sin duda, un sólido argumento a favor de la hipótesis de una mejora en la distribución de la tierra en el período señalado ${ }^{15}$. Sin embargo, la consideración

15. No obstante, es importante tener en cuenta que la disminución en el número relativo de jorna- 
de los partidos andaluces y extremeños nos lleva a obtener unas conclusiones bastante distintas. En una gran mayoría de estos partidos, el problema de la alta salarización no sólo no se corrigió, sino que se agravó, y de forma sustancial en algunos casos. Los partidos en los que más se deteriora el grado de acceso a la tierra son aquellos que partían de niveles de salarización medio-altos en 1860. Así pues, en términos generales, el nivel de salarización en España disminuyó en aquellos partidos judiciales en los que el problema en 1860 era, en términos relativos, de menor calado, pero se mantuvo o se agravó precisamente en aquellos partidos en los que el problema era inicialmente más grave (partidos andaluces y extremeños), algo confirmado por Maurice (1989:70) con datos parecidos. Una reciente investigación a partir de los datos fiscales de las herencias ha demostrado que la presencia de adultos con alguna riqueza creció de 1911 a 1935 en varias regiones españolas con la importante excepción de Andalucía, donde esa presencia apenas tuvo variación en ese período (Alvaredo \& Artola, 2015).

Por tanto, puede considerarse que «el mercado» (la reforma agraria liberal del siglo XIX), lejos de asegurar a los campesinos sin tierra la posibilidad de adquirirla, pudo actuar como un agravante del problema en aquellos lugares en los que el número de jornaleros sin tierra ya era alto (Robledo \& González Esteban, 2016). El mercado, por sí solo, no habría actuado entonces como un estabilizador que lleva al equilibrio, sino como un potenciador de los desequilibrios y desigualdades regionales. Afirmación provisional que será tanto más consistente cuanto más podamos robustecer los datos del Censo de Campesinos.

Carmona y Rosés aseguran que market forces were improving the situation of agrarian workers and their possibility of acquiring land without any particular policy (2011: 17). Los datos que estamos manejando cuestionan esta aseveración y reforzarían la hipótesis de que el mercado de la desamortización, sobre todo en la segunda mitad del xIX, dejó fuera a amplios segmentos de la población rural. No es el momento ahora de abordar el debate de la reforma agraria liberal y sus consecuencias, pero sí de cuestionar una visión excesivamente benevolente del cambio social agrario español que sin duda permitió ampliar el número de propietarios como quería Mendizábal (su copiosa familia de propietarios), pero con limitaciones ${ }^{16}$.Y es que concluida la fase de los repartos de la desamortización

leros sin tierra en las provincias del norte podría en algunos casos estar reflejando migraciones interprovinciales y no necesariamente mejoras en la distribución de la tierra. Como afirma López Estudillo: en Galicia, León, Zamora, y todas las provincias del Cantábrico, las explotaciones agrícolas apenas contrataban como trabajo asalariado una vigésima o una décima parte del trabajo total, lo que lejos de definir una arcadia feliz, contribuye a explicar las masivas migraciones del pasado de quienes precisaban trabajar como asalariados (2006: 64).

16. Algunas dudas sobre la dinamización del mercado de tierras como efecto automático de la revolución liberal, en Congost y García Orallo (2015). 
silenciosa, el jornalero estricto resultaba por definición excluido del mercado desamortizador, pues su empleo, cuando lo tenía, apenas si cubría el coste de la supervivencia.

Por último, creemos discutible la utilización que se hace de la tesis de la «normalización» de España: the relative importance of landless labourers in Spain was not significantly different to other countries (Carmona, Rosés \& Simpson, 2015:3). Supongamos que, pese a lo expuesto, demos por buena la cifra de un $30 \%$ de jornaleros en la población activa agraria, comparable a la de Francia. Es muy diferente que esa estimación refleje un promedio del que no se apartan mucho las regiones de cada país, a que sea el resultado de grandes disparidades, como sugieren nuestras observaciones. Por eso, el problema agrario español de 1930 no era equiparable al francés. Una forma de verlo es la consideración de los niveles básicos (el hambre, a veces) que agitaban en España la cuestión agraria meridional, mientras que en Francia se hablaba de vacaciones pagadas en la legislación del Frente Popular (Alexander \& Graham, 1989) y en Inglaterra de ciudades jardín para descongestionar la industria.

Ciertamente, existió un optimismo diletante sobre las posibilidades de parcelación del latifundio, pronto desmentidas por los técnicos (Robledo \& González Esteban, 2016), asunto sobre el que se incide en el último escrito de Carmona y Simpson (2015). No podemos extendernos sobre este tema pero sí indicar la viabilidad de la reforma para paliar estallidos sociales. En el otoño de 1932 Badajoz estaba a punto de convertirse en un inmenso Castilblanco, como expuso Vidarte ${ }^{17}$. Los decretos de intensificación de cultivos de 1 de noviembre de 1932 y el nombramiento dos semanas después de un delegado especial del Gobierno (gobernador general de Extremadura) con amplias facultades ejecutivas (nada menos que las de la Ley de Defensa de la República de 21 de octubre de 1931) sirvieron para controlar la situación. El éxito fue rotundo, reconoció Vázquez Humasqué. Unos 33.000 yunteros extremeños encontraron tierras que barbechar y después sembrar. En realidad, como apuntó Sánchez Román, se habían seguido los criterios ejecutivos de la Comisión Técnica Agraria que él había presidido en el verano de $1931^{18}$. En marzo de 1936 de nuevo fue Badajoz el epicentro de la reforma agraria española; la reforma estaba siendo un éxito hasta que el golpe militar la frustró (Espinosa, 2007).

17. DSSC, 6 de octubre de 1932, p. 8.792 .

18. Vázquez Humasqué, BIRA, n. ${ }^{\circ} 11$, marzo de 1933, p. 259; Sánchez Román, DSSC, 20 de junio de 1933, p. 13.516. Para este tema, Robledo (1996: 273-279); RiESCO (2007). 


\section{LA POLÍTICA LABORAL COMO CAUSA DE LA CONFLICTIVIDAD RURAL ${ }^{19}$}

El mercado de trabajo rural durante la Restauración funcionaba con una desigualdad institucionalizada entre oferta y demanda que estaba cubierta con el velo de la libertad de trabajo sostenida por la Guardia Civil, figura familiar del paisaje latifundista, a la que agasajaban los grandes propietarios ${ }^{20}$. Incluso llegó a instalarse el cuartelillo dentro de la misma finca ${ }^{21}$. Sin la Guardia Civil era imposible garantizar la libre entrada de obreros forasteros (especialmente de portugueses en Andalucía occidental, Extremadura y Salamanca), gracias a los cuales se conseguía a la vez deprimir los salarios e impedir el arma de la huelga. La estrategia era perfecta y se sostenía en el triángulo institucional formado por el gobernador civil, el alcalde y la Guardia Civil, que permitía mantener los modelos disciplinarios de trabajo a los que se han referido Naredo y Sumpsi (1984).

Para la patronal sevillana, la contratación tenía que ser directa e individual (la negociación colectiva se consideraba algo aberrante), debía existir libre concurrencia de mano de obra sin someterse a la restricción de las bolsas de trabajo ni a las reivindicaciones que cuestionaban la jornada de sol a sol, el destajo o la utilización de las máquinas (Florencio, 1994: 290-304). La reforma laboral republicana trastocó este universo tradicional. La regulación del mercado de trabajo rural se concretó en el establecimiento de la jornada de ocho horas, de los jurados mixtos de patronos y obreros, y en el decreto de términos municipales, que obligaba a los patronos a emplear preferentemente a los braceros vecinos del municipio. Se trató de una disposición polémica, conocida como ley de fronteras, sujeta a revisión de inmediato. Por último, el laboreo forzoso buscaba anticiparse a la reacción patronal de dejar las fincas en barbecho o erial, medida a la defensiva más para evitar que bajara el nivel de empleo que incentivo para animar a roturaciones indiscriminadas (Malefakis, 1971: 200-206; Robledo, 1996: 302-315).

La reforma laboral suscitó un amplio rechazo de las fuerzas conservadoras, que vieron cómo peligraba el marco institucional favorable a las negociaciones dictadas por la ley del más fuerte. En la historiografía española está extendida la crítica a la política laboral de la República, pues en vez de elevar el nivel de vida del jornalero, lo que hizo fue

19. El tema de la legislación socialista es muy complejo, dados los cambios en el funcionamiento de los jurados mixtos o en la aplicación de la ley de términos municipales. La bibliografía es amplísima. Un resumen en MALEFAKIS (1971: 200-206); GARRIDO (1987); ROBLEdO (1996: 302-315). Más recientemente, GARRIDO (2012).

20. Así lo recogen puntualmente las contabilidades (NAREDo \& SUMPSI, 1984: 49).

21. Ocurrió en Redrojo, propiedad del marqués de Lorenzana (MÉndez Mellado, 2015: 254). 
disminuirlo al incrementarse el paro. Más de un historiador le atribuye también la responsabilidad de la conflictividad social (Montañés, 1997:153).

Esta tesis ha sido desarrollada sistemáticamente por $\mathrm{Cobo}^{22}$, quien desde hace años ha estudiado la segmentación del campesinado en las zonas de latifundio de los años treinta con la perspectiva internacional de los movimientos sociales en Europa. Si resumimos el planteamiento, estaríamos ante: a) un conflicto intracampesino; b) provocado por la legislación reformista; c) cuya consecuencia fue la derechización del pequeño campesino.

La causa principal -y cronológicamente la primera- se sostiene sobre los enfrentamientos en la parte baja de la pirámide social a causa de la legislación laboral, que actuó como aceleración e intensificación de los conflictos intracampesinos. Cobo argumenta bien el modo en que las pequeñas y medianas explotaciones jienenses tuvieron que adaptarse después de la crisis finisecular a las condiciones del mercado mundial y, por tanto, se encontraron más expuestas a las fluctuaciones de la economía internacional y, en consecuencia, a la subida de costes que supuso la nueva legislación.

Aunque no se oculta cómo la patronal se dedicaba a burlar la ley y a boicotear las bases de trabajo, creemos que el relato de Cobo peca de cierta ambigüedad cuando afirma con contundencia que su investigación demuestra sobradamente el escaso papel jugado por los grandes propietarios rústicos en el proceso de acentuación del conflicto rural que registraron las tierras jiennenses durante el período de la Segunda República. Si bien se opta por hacer alguna matización, se sigue sosteniendo que los propietarios latifundistas cumplieron un papel secundario en el proceso de agudización de la conflictividad rural del primer tercio del siglo $\mathrm{XX}$ (Cobo, 2003: 125).

El otro punto discutible es la forma de enfocar el importante grado de conflictividad que sin duda tuvo lugar durante 1931-1933 y sus consecuencias sociales y políticas. La legislación laboral, calificada de extremadamente beneficiosa para los jornaleros [...] favoreció extremadamente su capacidad reivindicativa exigiendo el estricto cumplimiento de la legislación social o laboral o su interpretación progresista, como si la aplicación de la ley tuviera diversas escalas ${ }^{23}$. Con este relato, se favorece la interpretación de que el colec-

22. Son numerosas las publicaciones de este autor-citadas parcialmente en las Referencias- donde desarrolla esta tesis, alguna de las cuales difiere de planteamientos anteriores (Cово, 1992). La obra de este autor es referencia imprescindible, entre otros temas, para el estudio de la FNTT (Сово, 2007) o de las actitudes políticas del campesinado europeo en el período de entreguerras (Сово, 2012).

23. Estas expresiones se repiten en Сово (2003: 227, 258; 2011:220; 2012: 394-399; 2013). 
tivo de los jornaleros mantuvo una rigurosidad que no ayudó a la paz social. No queremos ser injustos con esta interpretación, pues el autor se refiere también a la contumaz resistencia patronal, pero el énfasis se pone más en la movilización projornalera con unas exigencias que no hacían más que mermar la rentabilidad de las explotaciones. De forma similar Fusi y Palafox vincularon la agudización de las tensiones sociales con el aumento de los salarios ${ }^{24}$.

Sin embargo, en nuestra opinión, había en las movilizaciones motivaciones muy inmediatas que no era fácil posponer, pues se trataba de la supervivencia misma. No hace falta más que leer los telegramas del alcalde de Navas (Jaén) al ministro (Urge solución crisis de trabajo. El hambre se extiende como reguero pólvora, 2 de octubre de 1931), del gobernador de Jaén al ministro (Estoy preocupado por no tener solución el paro obrero [...] hasta en número de 30 pueblos donde el problema es materialmente de hambre y donde se conformarían con un jornal alterno de tres pesetas, 30 de septiembre de 1931) o de los diputados socialistas al ministro de Gobernación el día siguiente (Creemos conveniente ordene Gobernador Civil haga cumplir lo pactado, caso contrario surgirán protestas [...] Hay que vencer situación angustiosa trabajadores hasta mediados de noviembre, por lo menos, que comience recolección aceituna) ${ }^{25}$. Son testimonios cualitativos para matizar la idea de un paisaje social dominado por la presión jornalera «ortodoxa» con la legislación social, que, por otra parte, como reconocen los expertos, no era tan radical $^{26}$.

En el relato de Cobo, la presión del sindicalismo socialista tuvo también consecuencias políticas: a diferencia de lo que ocurrió en los países nórdicos, el pequeño y mediano propietario/arrendatario hizo el viraje hacia los partidos conservadores ${ }^{27}$, de modo similar a lo que expuso Luebbert (1997) para otros lugares. Este tema del fracaso socialdemócrata es de gran calado y desborda claramente este comentario historiográfico. Únicamente habría que preguntarse hasta dónde son pertinentes las comparaciones. Desde fines del siglo XIX se había desarrollado en esos países un concepto de sociedad civil en el que los intereses de la economía nacional estaban por encima de los intereses econó-

24. La impaciencia en reivindicar mejoras en los salarios, que eran incompatibles con los niveles de productividad mayoritarios denotaba el atraso político y social de España (FUSI \& PALAFOX, 1997: 282-283).

25. Archivo Histórico Nacional (AHN), Gobernación, serie A, leg. 6, expte. 15.

26. Teniendo en cuenta las restricciones de huelgas, los mecanismos expeditivos para la solución de conflictos y la Ley de Orden Público de 1933 la legislación en materia de conflictos de la Segunda República era, ciertamente, una legislación muy moderada (MARTÍN VALVERDE, 1987: LXXXIV).

27. Fue un cambio de actitud que guardó una relación directa [la cursiva es nuestra] con las disputas cotidianas en torno a la propiedad de la tierra o del trabajo (Сово, 2003: 336). Aunque se enumeren otros factores, la política laboral y la reforma agraria serían las que hicieron girar al campesinado intermedio hacia la derecha (Сово, 2011: 220, 234-235). 
micos privados y un principio social que preservaba la cohesión social (Kettunen, 2009). Dinamarca, Noruega, Suecia y Finlandia habían puesto las bases a principios del siglo Xx de acuerdos colectivos entre trabajadores y empresarios que desarrollaban medidas propias del estado de bienestar ${ }^{28}$. Además de la diferente estructura social, la historia ciertamente no se improvisa.

Cobo expone convincentemente la variación del voto en 1933 con diversas correlaciones en función de la estructura social (Cobo, 2003: 275; 2012: 355). Creemos que es discutible por reduccionista el énfasis en los perjuicios causados por la legislación laboral como causa del giro electoral. La desnudez del voto depositado en la urna impide esclarecer la motivación fundamental del sentido de la votación o discriminar las influencias materiales de las ideológicas. ¿Por qué tuvieron que pesar sólo o más las reivindicaciones de los jornaleros que perjudicaban a pequeños propietarios? ¿Qué lugar se le asigna, por ejemplo, al descontento por la legislación laicista de tanto impacto en las comunidades rurales? Por otra parte, el pequeño propietario no siempre fue «agredido» por la reforma laboral: se aprovechó también de ella cuando trabajaba como obrero y si era colono se benefició de la congelación de rentas que facilitaron los decretos de revisión. Por último, junto a las motivaciones por exceso (la subida salarial que forzaron los obreros), se podría contemplar más la influencia de las motivaciones por defecto (la falta de aplicación de la reforma agraria).

El esquema reivindicación obrera $>$ aumento salarial $>$ quiebra de pequeñas empresas agrarias $>$ voto derechista se completa con la cooptación por la derecha del pequeño campesino desencantado en las elecciones de 1933. El caso salmantino al que se alude más de una vez (Cobo, 2011) demuestra que ese fenómeno es mucho más temprano. El Bloque Agrario, embrión de la CEDA ( (Por la Agricultura, por la Patria!) se organizó a principios de junio de 1931, siendo controlado al final por Gil Robles y los monárquicos que apaciguaron el entusiasmo republicano en las elecciones de 28 de junio (Robledo, 2007). Además, hay que contar con la política electoral. Como es sabido, una parte importante del éxito de las derechas en las elecciones de 1933 se debió a su capacidad organizativa (la coalición antimarxista), de la que careció la izquierda, a lo que hay que añadir la táctica abstencionista de la CNT. En suma, sin descartar la negativa influencia que pudiera tener el movimiento sindical en las actitudes del pequeño campesinado, conviene valorar la complejidad social, ideológica y política. Igualmente merece la pena no que-

28. Los principios del laboratorio social escandinavo, cuyos experimentos resultaron irrepetibles, fueron recogidos, no creados, por los partidos socialdemócratas en los años treinta (BALDwIN, 1992: 97-158). El seguro de desempleo se estableció en Noruega en 1906, en Dinamarca en 1907 y en Finlandia en 1917 (HERRANZ, 2010: 64). 
darnos en la oscilación del voto hacia la derecha en 1933, pues cambió de sentido en 1936, cuando izquierdas y republicanos de izquierda consiguieron en Andalucía el 54,35\% de los votos, porcentaje mayor que en $1931^{29}$.

Encontramos cierta semejanza con esta línea de argumentación en las investigaciones de Domenech $(2013,2015)$, quien atribuye la movilización social a la acción de los gobiernos republicanos (que él simplifica en top down), minimizando la importancia de los condicionantes materiales de los niveles de vida (bottom up) ${ }^{30}$. En Domenech (2013) la importancia atribuida a acciones top down se manifiesta singularmente en el argumento referido a la movilización de los trabajadores rurales: al ser mayoritariamente analfabetos se requiere generalmente la intervención del Estado ${ }^{31}$. Esta afirmación casa mal con varias evidencias, pues conocemos bien las causas de buena parte de la conflictividad, que se concretaba en la invasión de los domicilios de patronos requiriendo trabajo en la ocupación de las fincas. Ya hemos dado cuenta antes de algunos de estos testimonios para la provincia de Jaén que son extensibles a otras provincias ${ }^{32}$.

Si añadimos la información que proporcionan las discusiones del Diario de sesiones de las Cortes $^{33}$, o las anotaciones de los Diarios de Azaña ${ }^{34}$, es difícilmente sostenible la tesis de que la conflictividad rural fuera debida principalmente al cambio de la política laboral del Gobierno. Extrañamente, el autor no toma en consideración la importancia del paro agrario, que se multiplicó por más de dos entre 1932-1936 (Malefakis, 1971:

29. Сово (2000: 125). El diferencial se amplía si a la candidatura de centroizquierda se añaden "otros» (republicanos federales, autónomos e independientes). El giro electoral de 1936 respecto de 1933 se ha comentado mucho menos que el contraste 1931-1933.

30. the impact of decisive labour market intervention on collective action caused [cursiva del autor] the rise of rural militancy (DOMENECH, 2013: 88).

31. In a largely agrarian country with an underdeveloped mass education system, collective action problems were generally so severe as to require top-down state intervention to mobilize rural workers (DOMENECH, 2013: 106). Tal como se plantea, esta afirmación contradice toda la historia de los movimientos sociales y obliga a cuestionarse, por ejemplo, la existencia de acciones colectivas como las anarquistas que, por definición, iban contra el Estado.

32. Centenares de telegramas reflejan idéntica situación a la descrita antes para Jaén. AHN, Ministerio de Gobernación, serie A, leg. 6. Diversos expedientes. Provincias de Cáceres, Cádiz, Ciudad Real, Córdoba, Granada, Jaén, Málaga, Toledo. Para Badajoz, MÉndez Mellado (2015).

33. Por ejemplo, DSSC, 20 de octubre de 1932, p. 9.005 (Badajoz), 6 de febrero de 1934, p. 918 (Cáceres), 23 de marzo de 1934, pp. 1.776-1.780 (Almería).

34. El paro forzoso en Andalucía es gravisimo. Están en Madrid todos los alcaldes de la provincia de faén, a pedir dinero, y no se atreven a regresar a sus pueblos. Parece que hay necesidad de gastar dos millones diarios, durante tres meses, para que la gente no se muera de hambre y no se insurreccione. Anotación del 21 de julio de 1931 (AZAÑA, 1981: 48). Ante las invasiones de fincas, escribe: Los pequeños agricultores se mueren de hambre, $y$ muchos propietarios se niegan a dar tierra y trabajo ¿Pedirán que nos limitemos a rechazar las invasiones a tiros? Anotación del 22 de enero de 1933 (AZAÑA, 1997: 145). 
331). Es cierto que el promedio español de los salarios reales creció de 1931 a 1936, pero el ascenso salarial fue acompañado por un paro forzoso creciente. Si se exceptúan las provincias de Huelva, Almería y Sevilla, donde el peso de la minería, la construcción o alguna otra industria diversificaba la actividad económica, ocho o nueve de cada diez parados de las provincias latifundistas andaluzas procedían del sector agrario ${ }^{35}$. A fines de 1932 el 45\% de los jornaleros de la provincia de Badajoz estaban en paro según el Informe efectuado por el gobernador general de Extremadura a partir del Censo de Campesinos ${ }^{36}$. Nos estamos refiriendo a los desempleados agrarios, un colectivo desprotegido de cualquier subsidio.

No hace falta citar a Tocqueville o a Gramsci para poner en duda que la miseria conduzca por sí sola a la revolución, pero de los que se han empobrecido puede esperarse otro comportamiento, especialmente si el cambio de escenario político favorece las expectativas o la expresión de los temores. Frente a la teoría de la elección racional de Olson, que sigue el autor, la gente puede participar en la acción colectiva para reafirmarse personalmente o sentir agrado por sus acciones (Hirschman, 1986: 89-91). Desde la ciencia política o la sociología histórica se ha demostrado que la gente se suma a los movimientos sociales como respuesta a las oportunidades políticas, y a continuación crea otras nuevas a través de la acción colectiva ${ }^{37}$.

El gran ausente del estudio de Domenech es el demandante de trabajo. Los problemas que se analizan son las huelgas y sus motivaciones o la influencia del Gobierno en la movilización de los sindicatos, pero no cómo se afrontó la regulación del mercado de trabajo desde la demanda y cómo pudo repercutir la actitud de los patronos en la movilización de los trabajadores. La disminución en la demanda de empleo no tuvo sólo motivaciones económicas. Los propietarios tendieron a no aceptar las bases de trabajo ni a los obreros sindicados (Antes me cortaría una mano...), o redujeron la oferta de tierras para penalizar a los colonos que discutían la renta (juicios de revisión de rentas). El efecto acumulativo de esta doble discriminación sociopolítica concedió un poder de mercado

35. Boletín informativo de la Oficina Central de Colocación Obrera y Defensa contra el Paro (MINISTERIO DE TRABAJO, 1932-1933).

36. Se contabilizaron 88.032 jornaleros (no se incluyeron, aparceros o pequeños propietarios), de los que estaban en paro 39.268 (PEÑA, 1932: 1). Eso supondría que estaban en paro uno de cada cuatro activos de la agricultura según el Censo de 1930.

37. Éstas son las condiciones generales expuestas por Tarrow que se cumplen perfectamente en 1931 (TARROW, 2004: 49). La historiografía contemporánea hace años que ha descartado el bottom up como norma explicativa. Para el artículo seminal, véase Pérez Ledesma (1993). Un ejemplo entre tantos, GIL ANDRÉs (2000). Una excelente revisión de la literatura, en GonZÁlez CALleja (2002). 
al propietario para contrarrestar el poder sindical ${ }^{38}$. Si la afiliación al sindicato tenía el incentivo de conseguir fácilmente empleo (Domenech, 2013: 93), la reacción patronal trató de neutralizarlo con la destrucción de empleo. No tomar en consideración esto concede un poder excesivo a las organizaciones obreras, como si fuera posible cambiar de golpe $\mathrm{o}$ anular las relaciones que habían prevalecido tradicionalmente ${ }^{39}$.

En un trabajo posterior, Domenech matiza la importancia de la hipótesis del top down frente a las teorías tradicionales de bottom-up o las llamadas grievance-based theories of conflict (Domenech, 2015). En este caso el autor realiza un esfuerzo cuantitativo para explicar la conflictividad social durante la Segunda República. Para ello, cuenta con un panel de observaciones mensuales de 252 municipios pertenecientes a Córdoba, Jaén y Sevilla entre abril de 1931 y julio de 1934 . Una serie de ejercicios econométricos lleva al autor a reafirmarse en su tesis respecto de la escasa importancia de factores «estructurales» como el nivel de vida o el grado de desigualdad, en la explicación de la conflictividad social. Asimismo, el autor vuelve a enfatizar el gran poder explicativo de variables como el acceso a mercados y a la información, y también el de la acción institucional, capaz de alterar el poder de negociación de los trabajadores. No obstante, en este trabajo también se recalca que la miseria y la explotación eran una realidad inapelable en la Andalucía de la Segunda República y se reconoce que the mechanisms through which topdown processes of political and institutional change translate into bottom-up mobilization are still poorly understood (Domenech, 2015: 281).

Este artículo supone una valiosa contribución en la medida en que permite avanzar en el conocimiento e identificación de variables potencialmente explicativas de la conflictividad social que las teorías más tradicionales han tendido a dejar de lado, y en él se realiza un notorio esfuerzo por demostrar que, en una mayoría de los casos, el desencadenante último de la conflictividad no fue un descenso de los niveles de vida. Sin embargo, posiblemente el autor vaya demasiado lejos al utilizar sus regresiones para atribuir pesos explicativos de la generación del conflicto, y en concreto al afirmar que los factores estructurales (desigualdad o cambios en los niveles de vida) fueron relativamente poco importantes (Domenech, 2015: 280). Al margen de que la bondad relativa de la cosecha sea un proxy demasiado imperfecto del grado de miseria o desigualdad -y en cambio no se contemple la importancia del aumento del paro-, el principal problema es que la mues-

38. Algunos ejemplos en Sigler (2000: 43); Martín Villodres (1932: 50-51, 113); PeÑa (1932: 12); MALEFAKIS (1971: 307); CABRERA (1983); MONTAÑÉs (1997: 142).

39. Por razones de espacio, no ha sido posible comentar otros argumentos cuantitativos, que consideramos discutibles, como el diferencial entre los salarios de verano/invierno, que habría subido por la Ley de Términos Municipales, y la correlación entre huelgas y algunas variables sociales o demográficas. 
tra utilizada no incluye municipios en los que el desempleo o la explotación laboral no fueran una realidad cotidiana. En este sentido, es normal que los coeficientes asociados a las variables que supuestamente recogen el nivel de vida o la gravedad de los agravios laborales tengan poco poder explicativo en las regresiones. Si se acepta que el malestar social, el hambre y la explotación sistemática eran características comunes a todos los municipios que conforman la muestra, no parece que la estimación de un modelo econométrico sea la herramienta más adecuada para discernir en qué medida estas variables fueron importantes en la generación de conflictos. Interpretar la falta de significatividad de los coeficientes como una menor importancia de los factores estructurales frente a una mayor relevancia de las variables asociadas a procesos top-down supone perder de vista el origen del problema: una serie de condiciones materiales, percibidas socialmente como injustas, que efectivamente motivaban y eran condición necesaria para la existencia de amplias reivindicaciones grupales.

Podemos resumir ahora la argumentación para establecer una visión de conjunto ${ }^{40}$. La patronal agraria había disfrutado en los años inmediatos a la llegada de la República de un período en el que las estadísticas apenas registraron huelgas: era la situación soñada por los empresarios y la que añoraban los economistas que escribieron durante los años 1930, atribuyendo la crisis económica a la inestabilidad social (Comín, 2011: 65). A diferencia de los países de su entorno, los códigos de trabajo eran pactos aislados con un marco jurídico limitado. Aunque los gobiernos de la Restauración fueran institucionalmente sensibles al reformismo a través del Instituto de Reformas Sociales, su comportamiento fue constitucionalmente restrictivo con los derechos sindicales. Las circunstancias de «guerra social» del llamado trienio bolchevique (1918-1920) facilitaron cierta apertura, a la que ayudó la carta fundacional de la OIT que había firmado España, pero no se abordó entonces el tema de la negociación colectiva. El giro decisivo se produjo con el Gobierno provisional de la República y la aplicación del programa de Largo Caballero, que concedió los derechos sindicales necesarios para la negociación colectiva y acomodó España a la institucionalización de las políticas sociales de otros países (Barrio, 2014: 124, 130, 135, 170-190). Se trataba de la constitucionalización del derecho del trabajo, dándose los primeros pasos para un Estado social. Este objetivo supuso reorganizar la estructura administrativa del Ministerio de Trabajo y, por eso, Largo Caballero defendió siempre que el nombramiento de cualquier cargo en la red de instituciones ministeriales debía hacerlo

40. No comentamos otras tesis como la de Macarro, quien goza de cierta influencia en la historia contemporánea, según la cual la política laboral socialista no fue fruto de una doctrina económica mínimamente elaborada, sino algo así como un despropósito de Largo Caballero que al propiciar el alza salarial arruinó a los agricultores (MACARRO, 2000: 193). La revisión crítica de los planteamientos de este autor que sostiene la tesis de las insensateces de las reformas sustentadas en objetivos ideológicos que conducían a la irracionalidad económica, en ROBLEDo (2017). 
el Estado dándole carácter funcionarial, lo que lo alejaría de todo tipo de presiones políticas ${ }^{41}$.

Esta interpretación sobre la convergencia institucional de la legislación española con la europea no busca ocultar las dificultades de aplicación ni, por ejemplo, la utilización irregular que pudieron hacer los sindicatos imponiendo a los propietarios el turno forzoso de contratación de determinados obreros, algo que el Ministerio reconoció y trató de corregir ya tardíamente ${ }^{42}$. Simplemente llama la atención sobre el marco institucional en el que se integraba la legislación republicana, que es el que se ha desarrollado en la mayor parte de los países europeos occidentales después de 1945, un modelo de estado de bienestar actualmente en retroceso.Y ese marco no tenía por qué ser potencialmente conflictivo generando per se enfrentamientos irresolubles. En la exposición que, siguiendo fuentes hemerográficas, hace el mismo Cobo de la fuerte conflictividad del bienio 1931-1933 no son excepcionales los acuerdos. Así ocurrió en Arjona y Arjonilla en julio de 1932, en la importante huelga de abril de 1933 en Jaén, en junio de 1933 en Villanueva del Arzobispo, donde se aceptan parcialmente las severas condiciones de los jornaleros, y en Martos al mes siguiente, donde se acepta la propuesta de reparto de trabajo, y en octubre de 1933 en Lopera, donde los patronos se comprometieron a proporcionar trabajo a los más necesitados (Cobo, 2003: 224-258). En consecuencia, el sistema de jurados mixtos no impedía los pactos ni en la etapa obrerista. Por otra parte, si nos fiamos de los datos que proporciona el Anuario Estadístico, en 1933 la infracción de las bases en el sector agrario fue de 1 a 35, según fueran obreros o patronos, y las principales causas de las huelgas de 19321933 no fueron las relativas al salario, sino a la organización del trabajo y a la asociación $y$ personal (Robledo, 1996: 308).

El punto más polémico fue el Decreto de Términos Municipales, pero creemos que sería erróneo acusar a un decreto de la conflictividad social de obreros y patronos. La disposición aprobada el 28 de abril de 1931 (ley de 9 de septiembre) no surgió improvisadamente por una acción top down, que habría provocado la impericia de Largo Caballero, sino que intentó dar solución a un problema de imperfección de mercado que funcionaba monopsónicamente y con dumping social: era el caso de los portugueses, que, favorecidos por la devaluación monetaria del momento, causaban el doble perjuicio de restar ocupación a los españoles y rebajar el salario ${ }^{43}$. En el mercado laboral la capacidad de con-

\section{ARÓstegui (2013); VAldÉs (2006).}

42. Orden de 8 de noviembre de 1933 (Gaceta del 9 de noviembre de 1933).

43. Tal era la opinión de la prensa conservadora poco antes de la llegada de la República haciéndose eco de la indefensión del obrero español ante la inmigración de portugueses. $A B C, 11$ de enero de 1930, p. 25; $A B C, 12$ de julio de 1930. 
seguir trabajo depende del patrono, quien tradicionalmente contaba con la ventaja de información asimétrica y el poder de controlar el mercado sin ninguna regulación. Era este funcionamiento monopsónico el que se resistió a perder el gran propietario, mientras que la Ley de Fronteras quiso ser una respuesta -tanto menos inadecuada cuanto más se flexibilizara- para corregir aquella situación con la restricción de la oferta ${ }^{44}$. Dicha ley, de aplicación muy irregular por las excepciones y los incumplimientos, siempre se planteó por los socialistas como una medida provisional contra la depreciación salarial hasta que estuvieran en funcionamiento las delegaciones de trabajo.Y desde la historia del derecho del trabajo se ha argumentado que la lucha sindical del período republicano era la forma de suplir la escasez de mecanismos ordinarios (multas, indemnizaciones...) que garantizaran el cumplimiento de la normativa ${ }^{45}$. Al final la Ley fue derogada el 28 de mayo de 1934; el día 29 Salazar Alonso, ministro de Gobernación, declaró la cosecha servicio nacional y al día siguiente se estableció la previa censura ante la declaración de huelga en el campo para el 5 de junio por parte de la FNTT.

\section{CONCLUSIONES}

Tiende a descalificarse la Ley de Bases de 1932 como un severo error político, al no dar tierra al campesinado con el agravante de crearse enemigos sin necesidad: los pequeños propietarios incluidos en el Registro de la Propiedad Expropiable. No hay duda de que hubo errores. Pero las deficiencias legislativas no fueron producto sólo de la incompetencia de socialistas y republicanos de izquierda, sino también del éxito obstruccionista de la derecha y republicanos de centro. No debía de ser tan inútil la reforma de Azaña cuando tras el acceso de los gobiernos de centro-derecha en 1933 se recortaron o anularon los decretos de intensificación, se facilitaron los desahucios y se estableció la contrarreforma de 1935.Y no digamos lo que ocurrió cuando se aceleró la reforma en la primavera de 1936. Esto confirmaría la apreciación de Malefakis de que aquella ley era revolucionaria por sus implicaciones: amenazaba seriamente a la clase económica más fuerte del país, cortó las fuentes de crédito, dejaba gran parte de la tierra en una situación anómala, en la que no era controlada del todo ni por sus propietarios ni por el Estado, y excitaba las esperanzas del campesino empobrecido (1971: 297).

44. Un hombre conservador como el galleguista Peña Novo, gobernador general de Extremadura, no era partidario de su supresión, sino de su adaptación (PEÑA, 1932: 6).

45. MARTín VAlVERde (1977: 143). El número de inspecciones en toda España ascendió en 1931 a 896, menos que el año anterior por "reorganización del servicio». Anuario Estadístico, 1932-1933, p. 654. No hubo información en anuarios posteriores. 
La tesis expuesta en la primera parte de este trabajo avala una valoración muy positiva de las reformas liberales del siglo xIX por el desarrollo de un mercado activo y muy eficiente. Los precios de la tierra habrían sido más accesibles para los asalariados, cuyo número habría bajado en beneficio de los propietarios, mientras que en la Segunda República los intentos de reforma agraria no solo eran un sistema ineficiente para incrementar la producción y la productividad, sino que fracasaron en proporcionar una solución adecuada a la pobreza rural ${ }^{46}$. Uno de los problemas que tiene esta interpretación, según la cual, por decirlo de algún modo, las fuerzas del mercado se estaban encargando ya de la distribución, es que choca frontalmente con la opinión de la mayoría de los contemporáneos, no solo políticos, que defendieron la oportunidad de la reforma para apaciguar los conflictos asociados con la desigualdad de la propiedad. ¿Qué pasó para que ingenieros y economistas cualificados no percibieran que la situación de inequidad no era en realidad tan preocupante?

Con las consideraciones optimistas sobre el crecimiento económico español del primer tercio del siglo Xx, extensibles al sector agrario, puede suceder lo mismo que con las estimaciones actuales de crecimiento del PIB: la divergencia entre las cifras macroeconómicas y la realidad que soporta buena parte de la población. La Segunda República llegó con una situación de grave desempleo provocado por la desastrosa cosecha del olivar de Jaén y Córdoba. Después de la dictadura, la libertad de expresión del régimen republicano hizo visible la grave situación del campesinado, disimulada hasta entonces por la censura. Los informes de los gobernadores civiles a fines de 1931, vertidos en los telegramas al ministro de Gobernación, no hacen más que transmitir la impotencia para encontrar alguna solución al paro. Fue el desempleo forzoso, en efecto, la constante de la historia agraria republicana, que esperaba resolverse con la aplicación de la reforma agraria.

La comparación efectuada entre el Censo de 1860 y el Censo de Campesinos de 1930 demuestra el crecimiento del coeficiente de salarización en la España latifundista, es decir, de las posibilidades del paro.Y confirma una de nuestras hipótesis, expuesta no hace mucho: una alta desigualdad en la distribución de la riqueza de la que se parte inicialmente puede reproducirse a sí misma de un período al siguiente. Del mismo modo que se plantea el asunto de la asignación intergeneracional de recursos en la economía ecológica, una gran desigualdad hoy puede limitar el crecimiento de modo permanente (Robledo \& López García, 2007: 19).

46. CARMONA y SimpSON (2015). El concepto reformista del que partimos va más allá del cociente superficie/asentado del IRA (un dato sometido a distintas variables sobre el que no se discute ahora), y apuesta por la vía de la reforma agraria como el conjunto de medidas que permitía reducir la gran desigualdad social y sostener el régimen político republicano (RoBLEDO, 2008: 257). 
De otras consideraciones sobre la necesidad de la reforma agraria conviene recordar que la concentración de la propiedad de la tierra, al favorecer opciones extensivas, por principio expulsará empleo. Eficiencia social y eficiencia económica entran en conflicto. Esta opción difiere del modelo agricolizado, que está dirigido a maximizar el producto bruto y que absorbería trabajo (seguramente a costa de disminuir la productividad por hora trabajada, no por superficie) (Robledo, 2010). Recientemente se ha demostrado para el caso italiano que cuanto más desigual es la distribución de un activo no reproducible como la tierra, el equilibrio resultante se aparta más del caso competitivo, incentivando al propietario a demandar menos trabajo (Martinelli, 2014).

Conviene señalar, finalmente, que el aumento de la productividad conseguido a medio plazo con la redistribución no iba sólo, ni quizá principalmente, en la dirección agraria. Es presumible que la redistribución, además de solucionar los problemas de pobreza -entonces como ahora-, abría nuevas posibilidades a la formación, a las iniciativas comerciales y manufactureras -no sólo agrarias- propias de una sociedad en la que el margen de maniobra podía haber mejorado para muchos. Este mayor equilibrio social también tendría que haber favorecido a largo plazo negociaciones de contratos y acuerdos mercantiles y de tipo institucional más equilibradas (Gallego, 2007: 190-196).

Favorecer un nuevo marco de negociación en el mercado laboral fue justamente lo que propuso la política republicana para cambiar la ley del más fuerte acomodando España a la institucionalización de las políticas sociales de otros países. En la segunda parte del artículo se han analizado críticamente las opiniones que descargan sobre la legislación social rural el auge de la conflictividad y de la derechización de los pequeños propietarios.

Parece comprensible que el desarrollo de una reforma laboral favorable a los trabajadores del campo, que rompía con lazos de dependencia seculares, tuviera costes de adaptación con diversos desajustes, tanto para los trabajadores ahora sindicados ${ }^{47} \mathrm{como}$, sobre todo, para quienes tenían capacidad de dar trabajo. La hostilidad de los grandes labradores, que seguían teniendo poder económico y social, distorsionó la aplicación de la ley. Si se prescinde de esta variable, la interpretación, por mucha precisión cuantitativa que la acompañe, corre el peligro de ofrecer un conjunto desenfocado de la realidad. Lo que no se toleró, o resultó difícil de comprender, fue la aparición de unas nuevas relaciones de poder con unas reglas de juego hasta entonces inéditas en el campo. Más o menos como ocurre hoy, los patronos prometían trabajo con tal de que no hubiera regulación: ni Bases ni Bolsa [de trabajo] (López Martínez \& Gil Bracero, 1997: 306). Es-

47. No se trata en este trabajo de la dificultad que supuso la aplicación, dada la oposición de la CNT. 
taban bien los sindicatos cuando eran los católicos, pero era intolerable reconocer la personalidad social del sindicato y a sus delegados de trabajo, y permitir que manden en nuestras propias casas personas que nosotros no hemos designado para ello ${ }^{48}$. Prescindir de la enemistad antisindical o de la presión patronal, que podía cortar el grifo de la demanda de trabajo, como han demostrado todas las monografías, supone analizar muy parcialmente los conflictos del mercado de trabajo y pone en cuestión seriamente la tesis de que la pobreza, la desigualdad y el desempleo fueran casi irrelevantes para explicar la conflictividad social. Mucho más si los indicadores cuantitativos son cuestionables.

\section{AGRADECIMIENTOS}

Este trabajo se enmarca dentro del proyecto de investigación de la Universidad de Salamanca con referencia HAR2013-40760-R del Ministerio de Ciencia e Innovación.

En la elaboración de los datos del Censo de Campesinos de 1935-1936 ha sido muy valiosa la colaboración de Luis Enrique Espinoza y María Pilar Brel. Agradecemos los comentarios de Domingo Gallego, Luis Garrido, Miguel Ángel Malo, Juan Ignacio Palacio, y de los evaluadores anónimos de Historia Agraria.

\section{REFERENCIAS}

Alexander, M. S. \& Graham, H. (1989). Introduction. En A. Martin \& H. Grahan (Eds.), The French and Spanish Popular Fronts. Comparative Perspectives (pp. 1-8). Cambridge: Cambridge University Press.

Alvaredo, F. \& Artola, M. (2015). Wealth Concentration in Spain, 1900-2010: Local versus Global Forces. (Manuscrito).

Aróstegui, J. (2013). Largo Caballero: El tesón y la quimera. Barcelona: Debate.

AzAÑa, M. (1981). Memorias políticas y de guerra. Barcelona: Crítica.

AZAÑa, M. (1997). Diarios, 1932-1933: Los cuadernos robados. Barcelona: Crítica.

BALDWIN, P. (1992). La politica de solidaridad social: Bases sociales del estado de bienestar europeo, 1875-1975. Madrid: Ministerio de Trabajo y Seguridad Social.

Banco Mundial (2008). Informe sobre el desarrollo mundial 2008: Agricultura para el desarrollo. Washington, DC: Banco Interamericano de Reconstrucción y Fomento/Banco Mundial.

48. Rosado (1979: 69). La delegación patronal de Morón no ponía inconveniente a la parte económica. Queja similar (actuar bajo la férula de la Casa del Pueblo), en Robledo y Gallo (2009: 189). 
BARrio, A. (2014). Por la razón y el derecho: Historia de la negociación colectiva en España (1850-2012). Granada: Comares.

CABReRA, M. (1983). La patronal ante la II República: Organizaciones y estrategia (1931-1936). Madrid: Siglo XXI.

Carmona, J. \& Rosés, J. R. (2011). Was Land Reform Necessary? Access to Land in Spain, 1860 to 1931. Working Papers in Economic History, (01).

CARMONA, J. \& Simpson, J. (2015). Too Many Workers or not Enough Land? Why Land Reform fails in Spain during the 1930s. SEHA Working Paper, (1509).

Carmona, J., Rosés, J. R. \& Simpson, J. (2015). Spanish Land Reform in the 1930s: Economic Necessity or Political Opportunism? LSE Economic History Working Papers, (225).

Сово, F. (1992). Labradores, campesinos y jornaleros: Protesta social y diferenciación interna del campesinado jiennense en los orígenes de la Guerra Civil (1931-1936). Córdoba: Ayuntamiento de Córdoba.

Сово, F. (2000). El conflicto campesino en Andalucía durante la crisis de los años treinta (1931-1939): Un intento de revisión historiográfica. En M. GoNZÁLEZ DE MOLINA (Ed.), La historia de Andalucía a debate. I: Campesinos y jornaleros (pp. 103-134). Granada: Diputación Provincial de Granada/Anthropos.

Сово, F. (2003). De campesinos a electores: Modernización agraria en Andalucía, politización campesina y derechización de los pequeños propietarios y arrendatarios. El caso de la provincia de faén, 1931-1936. Madrid: Biblioteca Nueva.

Cово, F. (2007). Por la reforma agraria hacia la revolución: El sindicalismo agrario socialista durante la II República y la Guerra Civil (1930-1939). Granada: Universidad de Granada.

Сово, F. (2011). Campesinado, política y urnas en los orígenes de la guerra civil, 19311936. En M. T. ORTEGa \& F. Сово (Eds.), La España rural, siglos XIX y XX: Aspectos politicos, sociales y culturales (pp. 219-256). Granada: Comares.

Сово, F. (2012). ¿Fascismo o democracia? Campesinado y politica en la crisis del liberalismo europeo, 1870-1939. Granada: Universidad de Granada

Сово, F. (2013). La cuestión agraria y las luchas campesinas en la II República, 19311936. Hispania Nova, (11). http://hispanianova.rediris. es/11/dossier/11d002.pdf

Comín, F. (2011). Política y economía: Los factores determinantes de la crisis económica durante la Segunda República (1931-1936). Historia y Política, (26), 47-79.

Congost, R. \& GARCía ORALlo, R. (2015). Legislación hipotecaria y dinámica económica en la España de mediados del siglo XIx: De los oficios de hipotecas al registro de la propiedad. Congreso Internacional «Old and New Worlds: The Global Challenges of Rural History». Lisboa, enero de 2016.

Deaton, A. (2015). El gran escape: Salud, riqueza y los origenes de la desigualdad. México: Fondo de Cultura Económica. 
Domenech, J. (2013). Rural Labour Markets and Rural Conflict in Spain before the Civil War (1931-36). Economic History Revierw, 66 (1), 86-108.

Domenech, J. (2015). Land Tenure Inequality, Harvests, and Rural Conflict: Evidence from Southern Spain during the Second Republic (1931-1934). Social Science History, 39 (2), 253-286.

EsPinosa, F. (2007). La primavera del Frente Popular: Los campesinos de Badajoz y el origen de la guerra civil (marzo-julio de 1936). Barcelona: Crítica.

Espinoza, L. E., Robledo, R., Brel, M. P. \& Villar, J. (2007). Estructura social del campo español: El Censo de Campesinos. En R. Robledo \& S. López García (Eds.), ¿Interés particular y bienestar público? Grandes patrimonios y reformas agrarias (pp. 307-342). Zaragoza: Prensas Universitarias de Zaragoza.

FLORENCIO, A. (1994). Empresariado agrícola y cambio económico, 1880-1936: Organización y estrategia de la patronal sevillana en los inicios de la modernización. Sevilla: Diputación Provincial de Sevilla.

Fusi, J. P. \& Palafox, J. (1997). España 1808-1996: El desafío de la modernidad. Madrid: Espasa.

Gallego, D. (2007). Más allá de la economía de mercado: Los condicionantes históricos del desarrollo económico. Madrid: Marcial Pons.

GARRIDO, L. (1987). Legislación social y conflictos laborales en la provincia de Jaén (19311933). En J. L. García Delgado (Ed.), La II República española: El primer bienio (pp. 95-118). Madrid: Siglo XXI.

GARRIDO, L (2012). Nuevos estudios sobre la historia de la conflictividad laboral en Andalucía (1750-1982). Alcores, (14), 193-221.

GIL ANDRÉs, C. (2000). Echarse a la calle: Amotinados, huelguistas y revolucionarios (La Rioja, 1890-1936). Zaragoza: Prensas Universitarias de Zaragoza.

Gilens, M. (2012). Affluence and Influence: Economic Inequality and Power Politic in America. Princeton: Princeton University Press.

González CAlleja, E. (2002). La violencia en la política: Perspectivas teóricas sobre el empleo deliberado de la fuerza en los conflictos de poder. Madrid: Centro Superior de Investigaciones Científicas.

GonZÁleZ EstebAn, A. L. (2014). Nuevos paradigmas agrarios: Una aproximación a los fundamentos teóricos de la «soberanía alimentaria». Historia agraria, (64), 131-159.

HerRanz, A. (2010). La difusión internacional de los seguros sociales antes de 1945. En J. Pons \& J. Silvestre (Eds.), Los orígenes del estado del bienestar en España, 19001945: Los seguros de accidente, vejez, desempleo y enfermedad (pp. 51-84). Zaragoza: Prensas Universitarias de Zaragoza.

Hirschman, A. O. (1986). Interés privado y acción pública. México: Fondo de Cultura Económica. 
Kettunen, P. (2009). The Agent Called «Society» in the Making and Challenging of the Nordic Welfare State. 34 ${ }^{\text {th }}$ Annual Meeting of the Social Science History Association. Long Beach, 12-15 de noviembre.

López EsTUdillo, A. (2006). Los mercados de trabajo desde una perspectiva histórica: El trabajo asalariado agrario en la Andalucía Bética (la provincia de Córdoba). Revista Española de Estudios Agrosociales y Pesqueros, (211), 63-119

López EsTUdiLlo, A. (2011). Evolución de la desigualdad agraria en los siglos XVIII-XX en Aguilar de la Frontera (Córdoba). XIII Congreso de Historia Agraria. Congreso Internacional de la SEHA. Lleida, 12-14 de mayo.

López Martínez, M. \& Gil Bracero, R. (1997). Caciques contra socialistas: Poder y conflictos en los ayuntamientos de la República. Granada (1931-1936). Granada: Diputación Provincial de Granada.

LUEBBERT, G. M. (1997). Liberalismo, fascismo o socialdemocracia: Clases sociales y origenes políticos de los regímenes de la Europa de entreguerras. Zaragoza: Prensas Universitarias de Zaragoza.

Macarro, J. M. (2000). Socialismo, república y revolución en Andalucía (1931-1936). Sevilla: Universidad de Sevilla.

MALEFAKIS, E. (1971). Reforma agraria y revolución campesina en la España del siglo XX. Barcelona: Ariel.

MARTín VALVERDE, A. (1977). Colocación y regulación del mercado de trabajo agrícola. Agricultura y Sociedad, (3), 109-145.

Martín VAlverde, A. (1987). La legislación social en la historia de España: De la revolución liberal a 1936. Madrid: Congreso de los Diputados.

Martín Villodres. E. (1932). La verdad desnuda (Mi soviet en faén). Madrid: Impr. Sáez Hermanos.

Martinelli, P. (2014). Latifundia revisited. Market Power, Land Inequality and Agricultural Efficiency: Evidence from Interwar Italian Agriculture. Explorations in Economic History, (54), 79-106.

MAURICE, J. (1989). El anarquismo andaluz: Campesinos y sindicalistas, 1868-1936. Barcelona: Crítica.

Méndez Mellado, H. (2015). Por la tierra y el trabajo: La conflictividad campesina en la provincia de Badajoz durante la II República (1931-1936). Tesis doctoral inédita. Universidad de Extremadura.

Millán, J. (1999). El poder de la tierra: La sociedad agraria del Bajo Segura en la época del liberalismo, 1830-1890. Alicante: Instituto Alicantino de Cultura Gil-Albert.

MonTAÑés, E. (1997). Crisis agrícola y reformismo republicano: La instauración de la negociación colectiva en la campiña andaluza, 1931-1933. Revista de Estudios Regionales, (49), 133-160. 
NAREDO, J. M. \& Sumpsi, J. M. (1984). Evolución y características de los modelos disciplinarios del trabajo agrario en las zonas de gran propiedad. Agricultura y Sociedad, (33), 45-86.

Navarro, F. J. (2000). Crisis económica y conflictividad social: La Segunda República y la Guerra Civil en Tomelloso. Ciudad Real: Diputación Provincial de Ciudad Real.

PEÑA, L. (1932). Informe sobre la situación de las provincias de Badajoz y Cáceres. Archivo General de la Guerra Civil (AGGC), sección Político-Social Madrid, leg. 695.

Pérez Ledesma, M. (1993). Cuando lleguen los días de cólera: Movimientos sociales, teoría e historia. En M. MonTANARI et al. (Eds.), Problemas actuales de la historia (pp. 141-187). Salamanca: Universidad de Salamanca.

RIESCO, S. (2007). La intensificación de cultivos durante la reforma agraria de la segunda República: ¿Alternativa o complemento? En R. RoBledo \& S. López GARCía (Eds.), ¿Interés privado, bienestar público? Grandes patrimonios y reformas agrarias (pp. 363387). Zaragoza: Prensas Universitarias de Zaragoza.

Riesco, S. (2016). Un repaso al papel de la agricultura en la historiografía de la última década sobre la crisis de los años 30 en España. Congreso Internacional «Old and New Worlds: The Global Challenges of Rural History». Lisboa, 27-30 de enero.

Robledo, R. (1988). Crisis agraria y éxodo rural: La emigración española a ultramar (1880-1920). En R. GARRABOU (Ed.), La crisis agraria de fines del siglo XIX (pp. 212244). Barcelona: Crítica.

Robledo, R. (1996). Política y reforma agraria: De la Restauración a la II República (1868/74-1939). En A. García SANZ \& J. SANZ Fernández (Eds.), Reformas y politicas agrarias en la historia de España (pp. 247-349). Madrid: Ministerio de Agricultura, Pesca y Alimentación.

Robledo, R. (Ed.) (2007). Esta salvaje pesadilla: Salamanca en la guerra civil española. Prólogo de J. Fontana. Barcelona: Crítica.

Robledo, R. (2008). Los economistas ante la reforma agraria de la Segunda República. En E. Fuentes \& F. Comín (Coords.), Economía y economistas españoles en la guerra civil (pp. 243-276).Vol. 2. Barcelona: Galaxia Gutenberg/Real Academia de Ciencias Morales y Políticas.

RoBLEDO, R. (2010). El fin de la cuestión agraria en España (1931-1939). En R. ROBLEDO (Ed.), Sombras del progreso: Las huellas de la historia agraria (pp. 117-150). Barcelona: Crítica.

Robledo, R. (2017). La cuestión agraria en los años treinta: La nueva historia política y otras tendencias. En E. GonzÁlez CAlleja \& A. Ribagorda (Eds.), Luces y sombras del 14 de abril. Madrid: Biblioteca Nueva.

Robledo, R. \& Gallo, T. (2009). El ojo del administrador: Política económica de una aristocracia en la Segunda República. Ayer, (73), 161-194. 
Robledo, R. \& GonZÁlez, A. L. (2016). Sobre la necesidad de una reforma agraria en España (1931-1936). Documentos de trabajo AEHE, (1604).

Robledo, R. \& López García, S. (2007). Tiempo, instituciones y reformas. En R. RoBLEDO \& S. LÓPEZ GARCÍA (Eds.), ¿Interés particular, bienestar público? Grandes patrimonios y reformas agrarias (pp. 7-30). Zaragoza: Prensas Universitarias de Zaragoza. Rosado, A. (1979). Tierra y libertad: Memorias de un campesino anarcosindicalista andaluz. Prólogo de A. M. Bernal. Barcelona: Crítica.

RothsCHILD, K. W. (1957). Teoría de los salarios. Madrid: Aguilar.

Ruiz-Funes, M. (1936). La política agraria de la República. Boletín del Instituto de Reforma Agraria, (48).

SigLeR, F. (2000). La reforma agraria en Espera. Madrid:Tréveris.

Simpson, J. (1997). La agricultura española (1765-1965): La larga siesta. Madrid: Alianza.

TARRow, S. (2004). El poder en movimiento: Los movimientos sociales, la acción colectiva y la política. $2 .^{\text {a }}$ ed. Madrid: Alianza.

VALDÉs, F. (2006). El derecho del Trabajo en la Segunda República. En J. ArosteguI (Ed.), La república de los trabajadores: La Segunda República y el mundo del trabajo (pp. 176-207). Madrid: Fundación Largo Caballero. 